\title{
A INTERNACIONALIZAÇÃO DA INDÚSTRIA AUTOMÓVEL: A EMERGÊNCIA DAS PERIFERIAS EUROPEIAS (O CASO ESPANHOL)
}

\begin{abstract}
MÁRIO VALE ${ }^{1}$
A internacionalização dos sistemas de produção é um assunto particularmente relevante na investigação geográfica dos países mais desenvolvidos. No passado, os sistemas de produção encontravavam-se associados às economias nacionais, sendo poucos os casos de internacionalização da produção, pelo menos na Europa. Actualmente, no espaço da União Europeia (UE), a formação do Mercado Único e a ameaça japonesa levaram os principais fabricantes do sector automóvel a reorganizar as suas redes de produção. É neste contexto que se observa a emergência dos países periféricos da UE na produção automóvel, particularmente da Espanha, que é, actualmente, o terceiro maior fabricante de veículos automóveis, atrás da Alemanha e da França.

A tese de doutoramento de Arnoud Lagendijk ${ }^{2}$ incide, justificadamente, na emergência da Espanha quanto ao fabrico e montagem de automóveis. O trabalho do autor estrutura-se em dez capítulos que culminam numa conclusão geral. O primeiro capítulo traça os objectivos da tese de doutoramento que, basicamente, se podem resumir em três questões:

- Quais os factores que podem explicar a emergência de formas específicas de internacionalização de um sistema de produção industrial?

- Até que ponto o desenvolvimento organizativo e espacial da indústria automóvel pode ser explicado pelos factores identificados na resposta à questão anterior?

- Que factores justificam o processo de internacionalização da indústria automóvel espanhola; quais são os principais impactes, sectoriais e regionais, decorrentes daquele processo?

\footnotetext{
1 Assistente da Faculdade de Letras, Universidade de Lisboa. Investigador do Centro de Estudos Geográficos. Faculdade de Letras, Cidade Universitária, 1699 Lisboa Codex.

e-mail: ceg@mail. telepac.pt

${ }^{2}$ Lagendijk, Arnoud (1993) - The Internationalisation of the Spanish Automobile Industry and its Regional Impact. The Emergence of a Growth-Periphery. Thesis Publishers and Tinbergen Institute, Amsterdam, 295 pp.
} 
Por forma a responder à primeira questão, Lagendijk desenvolve três capítulos teóricos. O segundo capítulo incide na discussão das trajectórias industriais dos espaços nacionais e dos princípios de organização dos sistemas produtivos, prestando-se especial atenção à formação de redes de produção, onde se contrapõem os princípios de eficiência aos de poder económico. O terceiro capítulo dedica-se à análise crítica da aplicação dos princípios organizativos, discutidos no capítulo anterior, à indústria automóvel, com destaque para a análise das relações entre as linhas de montagem e os fornecedores de componentes. O último capítulo teórico (quarto) é, na nossa opinião, o mais original, ainda que se possa argumentar que, pelo desenvolvimento de teorias mais recentes, se encontra relativamente ultrapassado. Não obstante, Lagendijk apresenta uma teoria dinâmica do processo espacial de mudança industrial. A trajectória de um sistema industrial é, para o autor, o resultado da interligação do desenvolvimento do mercado e da estratégia das firmas dominantes; é da interacção destas duas forças que um sistema pode apresentar um maior ou menor nível de integração vertical e de concentração industrial. As duas situações extremas resultantes são aquilo que o autor designa por growth-periphery e growth-centre: a primeira decorre da resistência das firmas dominantes à criação de uma divisão do trabalho mais especializada, resultando na continuação do domínio das regiões centrais, que apenas procuram alargar as suas redes de produção às áreas mais periféricas, designadamente através do investimento das empresas transnacionais; no segundo caso, a expansão de mercados intermédios possibilita o desenvolvimento de novas actividades em novos espaços, criadas por agentes económicos independentes.

Nos dois capítulos seguintes, Lagendijk procura responder à segunda questão da sua tese. Assim, no quinto capítulo analisa-se o processo de reestruturação da indústria automóvel ao nível global, tendo como referência os princípios organizativos da lean production. O sexto capítulo ilustra as mudanças espaciais do sistema automóvel desde o início do século, igualmente à escala mundial, onde se detecta, nos anos mais recentes, a tendência para a formação de redes de produção em algumas áreas periféricas.

Os últimos quatro capítulos são dedicados à indústria automóvel espanhola e, portanto, resultam da necessidade de responder à última questão formulada no primeiro capítulo. Nos capítulos sete e oito, o autor apresenta uma breve evolução do sector, destacando três aspectos relevantes para a formação do sistema de produção automóvel em Espanha: a estratégia de formação de redes de produção dos principais fabricantes ao nível europeu; as condições favoráveis ao investimento daquelas empresas, designadamente os níveis salariais mais baixos e a possibilidade de usufruírem das vantagens dos fundos estruturais comunitários; a dimensão do mercado interno, atendendo a que os níveis de motorização, nos anos sessenta e setenta, ainda eram muito baixos. Sendo estes os factores-chave gerais 
que estimularam o desenvolvimento da indústria automóvel, o autor destaca ainda o papel da política industrial espanhola, que alternou entre a protecção da indústria nacional - Seat - e a atracção de investimento directo estrangeiro, sob condições muito restritas, por forma a melhorar a competitividade da indústria nacional de componentes. A estratégia de europeização dos construtores automóveis acabou, no entanto, por alterar a natureza do sistema de produção espanhol, porquanto se observou uma mudança de uma indústria integrada ao nível interno, mas isolada ao nível externo, nos anos sessenta e setenta para uma indústria integrada ao nível europeu, nos anos oitenta e noventa, mas em segmentos produtivos de menor valor acrescentado (linhas de montagem de veículos dos segmentos mais baixos).

No nono capítulo analisam-se as principais mudanças na geografia da indústria automóvel espanhola, que se traduzem, essencialmente, pela diminuição da concentração da actividade, que, até aos anos setenta, estava confinada sobretudo aos principais centros industriais. Os fluxos de capital estrangeiro vieram alterar esta situação, privilegiando áreas com menor tradição industrial. Destas áreas, Lagendijk estudou, no décimo capítulo, Valladolid (FASA-Renault), Vigo (Citroën) e Aragón (General Motors), tendo analisado o impacte regional das novas linhas de montagem da indústria de componentes para automóveis, nos outros sectores de actividade económica e no emprego. Na conclusão deste capítulo identificam-se como variáveis centrais para o desenvolvimento regional o tipo de investimento e a estratégia de selecção de fornecedores das linhas de montagem. Segundo o autor, as linhas de montagem têm beneficiado as respectivas regiões onde se instalaram, ao ponto destas constituírem, na actualidade, nós centrais no espaço económico espanhol.

Como nota final, pensamos que o trabalho de Lagendijk atingiu os objectivos a que se tinha proposto. Todavia, destacamos dois aspectos menos positivos. Em primeiro lugar, o autor não consegue desenvolver verdadeiramente uma nova teoria do processo espacial de mudança industrial, porquanto as suas orientações teóricas seguem de perto as teses da Nova Divisão Internacional do Trabalho. De acordo com a sua teoria, o autor conclui, porém, que a Espanha se enquadra no conceito de periferia em crescimento (growth-periphery), daí decorrendo uma dependência da indústria automóvel em relação às principais transnacionais dos países mais desenvolvidas da UE. Como segunda limitação, pensamos que os estudos de caso são relativamente superficiais, podendo mesmo afirmar-se que a investigação intensiva realizada é modesta. Não obstante, Lagendijk realizou um trabalho extremamente interessante, de grande utilidade para os geógrafos portugueses, tanto mais que Portugal atravessa um momento de desenvolvimento da indústria automóvel, polarizado igualmente por investimentos estrangeiros. 